\title{
Incorporation of Palm Kernel Shell into Fired Clay Brick
}

\author{
Aeslina Abdul Kadir ${ }^{1,}$, Noor Amira Sarani ${ }^{2}$, and Syafiqah 'Amirah Abd Kadir ${ }^{3}$ \\ ${ }^{1,2,3}$ Department of Water and Environmental Engineering, Faculty of Civil and Environmental \\ Engineering, Universiti Tun Hussein Onn Malaysia, 86400, Parit Raja, Batu Pahat, Johor
}

\begin{abstract}
Palm oil processing has produce agricultural waste and one of the wastes is palm kernel shell (PKS) which is abundance and creating disposal problems in landfill. Recently, many researchers investigate the incorporation of palm oil waste such as palm fiber, palm oil fuel ash and empty fruit bunch which could have potential as a second raw material in brick manufacture. Therefore, this study is to investigate the physical and mechanical properties of PKS as clay replacement in fired clay brick. Different percentages of PKS $(0 \%, 1 \%, 5 \%$ and $10 \%)$ were incorporated into fired clay brick. Manufactured bricks were fired at $1050^{\circ} \mathrm{C}$ with heating rate of $1^{\circ} \mathrm{C} / \mathrm{min}$ and were tested with dry density, shrinkage, initial rate of suction, water absorption, porosity and compressive strength. XRF result shows that both clay soil and PKS have a highest percentage of Silicon Dioxide $\left(\mathrm{SiO}_{2}\right)$ and Iron Oxide $\left(\mathrm{Fe}_{2} \mathrm{O}_{3}\right)$. Throughout this study, PKSB1\% shows the best result compared to others brick with several improvements on physical and mechanical properties. As the conclusion, PKS could be a potential waste to be utilized as it produces adequate brick with better strength and complied with the requirement.
\end{abstract}

\section{Introduction}

Production of palm oil assists Malaysia in terms of economical and also agricultural industry. However, the increased in palm cultivation has led to thousands of tonnes of palm oil waste in Malaysia. Milling process of fresh fruit bunch has produced abundant of palm oil waste such as palm kernel shell (PKS). By sending those agricultural wastes to landfills and disposed through incineration method is not the practical solution because those wastes will release high methane gas during incineration process that caused several environmental problems.

Numerous of researchers had studied incorporation of different types of waste into fired clay brick as an alternative method on maximize the utilization waste product in construction material [1-3]. Furthermore, recycle and reuse of waste product is a worthwhile activity with many beneficial effects to environment and construction field. Based on previous studies, incorporation of waste products into fired clay brick is generously showing the good agreement with others. Therefore, the aim of this study is to

* Corresponding author: aeslina@uthm.edu.my 
investigate the possible use of PKS into fired clay brick and its effect on the physical and mechanical effect as it gives positive impact to the environment.

\section{Materials and methods}

In order to measure the properties of manufactured brick, the materials and methods were discussed in this section.

\subsection{Materials}

The materials used in this study are PKS and raw clay soil. Upon delivery, raw clay soil and PKS was oven dried for 24 hours at $105^{\circ} \mathrm{C}$ and then was stored in closed containers. This process is needed in order to ensure that the samples are in dry condition before manufacturing process. The PKS collected from local palm oil mill was ground and sieved passed through $4.75 \mathrm{~mm}$ sieve to obtain homogenous size.

\subsection{Methods}

\subsubsection{Testing methods for raw clay soils and palm kernel shell}

Characterization of chemical composition was tested by using X-ray Fluorescence (XRF) method.

\subsubsection{Manufacturing process of control brick and palm kernel shell brick}

Once the raw materials have been characterized, raw clay soil was mixed with different percentage of PKS $(1 \%, 5 \%$, and $10 \%)$. Necessary amount of water was added to achieve desired consistency of the samples. The mixture then was pressed into mould of $215 \mathrm{~mm} \mathrm{x}$ $115 \mathrm{~mm} \times 65 \mathrm{~mm}$ with pressure of $3000 \mathrm{psi}$. Manufactured samples were oven dried at $105^{\circ} \mathrm{C}$ for 24 hours and then continued with firing process in furnace at $1050^{\circ} \mathrm{C}$ using heating rate of $1^{\circ} \mathrm{C} / \mathrm{min}$. Control brick also was manufactured for control purposed. The manufactured bricks were designed as Control Brick (CB) for the brick without PKS, and PKSB1\%, PKSB5\% and PKSB $10 \%$ for the brick with $1 \%, 5 \%$ and $10 \%$ of PKS, respectively.

\subsubsection{Physical and mechanical properties of manufactured brick}

Physical and mechanical properties of fired clay brick were tested such as dry density, shrinkage, initial rate of suction (IRS), water absorption, porosity and compressive strength that has been conducted at laboratory. All the test were carried out according to British Standards and the results are reported in three mean values [4].

\section{Results and discussion}

\subsection{Characterization of manufactured brick}

Chemical analysis of raw clay soil and palm kernel shell was carried out to determine the main component of the materials used in this study. The main oxides present in raw clay 
soil are $\mathrm{SiO}_{2}(55.7 \%), \mathrm{Al}_{2} \mathrm{O}_{3}(24.4 \%)$ and $\mathrm{Fe}_{2} \mathrm{O}_{3}$ (4.46\%). Meanwhile, other major components observed in palm kernel shell are $\mathrm{SiO}_{2}(22.58 \%)$ and $\mathrm{Fe}_{2} \mathrm{O}_{3}(34.37 \%)$.

\subsection{Physical and mechanical properties}

This study is focusing on the different percentages of palm fibre waste to be incorporated into fired clay brick in order to achieve desired performance on physical and mechanical properties.

\subsubsection{Dry density}

Dry density of the manufactured bricks is presented in Fig. 1 where the values were varied between $1646.93 \mathrm{~kg} / \mathrm{m}^{3}$ to $1915.91 \mathrm{~kg} / \mathrm{m}^{3}$ depending on the percentage of waste content. Based on the Fig. 1, CB gives the highest number of dry density which was $1915.9 \mathrm{~kg} / \mathrm{m}^{3}$ and followed by PKSB1\% and PKSB5\% with dry density $1844.6 \mathrm{~kg} / \mathrm{m}^{3}$ and $1761.5 \mathrm{~kg} / \mathrm{m}^{3}$. The lowest density of brick was obtained with the incorporation with $10 \%$ of PKS $\left(1646.9 \mathrm{~kg} / \mathrm{m}^{3}\right)$. From the results, all the manufactured brick are classified as high gross densities brick as their densities are over than $1000 \mathrm{~kg} / \mathrm{m}^{3}$ [5]. Lower density of brick is highly recommended since it could reduce load during construction work besides reduce logistic costs [6-8].

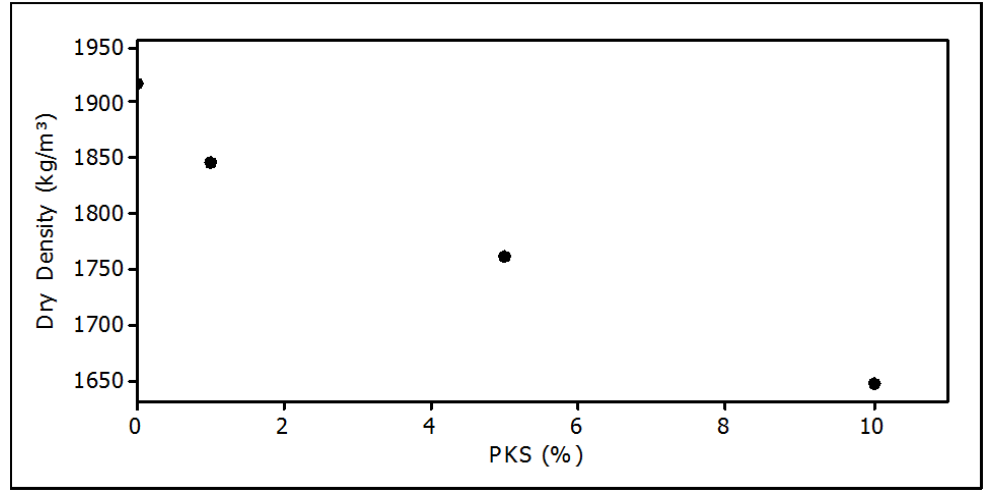

Fig. 1. Dry density of brick.

\subsubsection{Shrinkage}

Total shrinkage of the manufactured bricks is presented in Fig. 2 where total shrinkage values of the samples were varied within $0.75 \%$ to $1.75 \%$ depending on the percentage of waste content. As the PKS increased, the value of shrinkage also increased. The lowest was obtained by $\mathrm{CB}$ with $0.75 \%$. The result also found that total shrinkage increased with $0.93 \%$ (PKSB1\%), 1.43\% (PKSB5\%) and 1.75\% (PKSB10\%). The requirement has recommended that shrinkage falls within $2.5 \%$ to $10 \%$ [5]. Unexpectedly the results for all manufactured brick are in good agreement with the requirement.

\subsubsection{Initial rate of suction}

Initial rate of suction of the manufactured bricks is presented in Fig. 3 where initial rates of suction values of the samples were varied between $2.48 \mathrm{~kg} / \mathrm{m}^{2} . \min$ to $5.61 \mathrm{~kg} / \mathrm{m}^{2} . \mathrm{min}$ depending on the percentage of waste content. As the PKS content increased, the value of 
initial rate of suction also increased. Based on the result, PKSB10\% achieved maximum initial rate of suction which was $5.61 \mathrm{~kg} / \mathrm{m}^{2}$.min followed by PKSB5\% and PKSB $1 \%$ which was $3.50 \mathrm{~kg} / \mathrm{m}^{2}$.min and $3.29 \mathrm{~kg} / \mathrm{m}^{2}$.min respectively. Meanwhile, initial rate of suction for CB was $2.48 \mathrm{~kg} / \mathrm{m}^{2}$.min that makes CB obtained the lowest rate among the rest of the brick. However, all manufactured brick shows high initial rate of suction which is over than $2 \mathrm{~kg} / \mathrm{m}^{2}$.min. Therefore, brick should be wetted prior 3 hours to 24 hours before laid as suggested by [9].

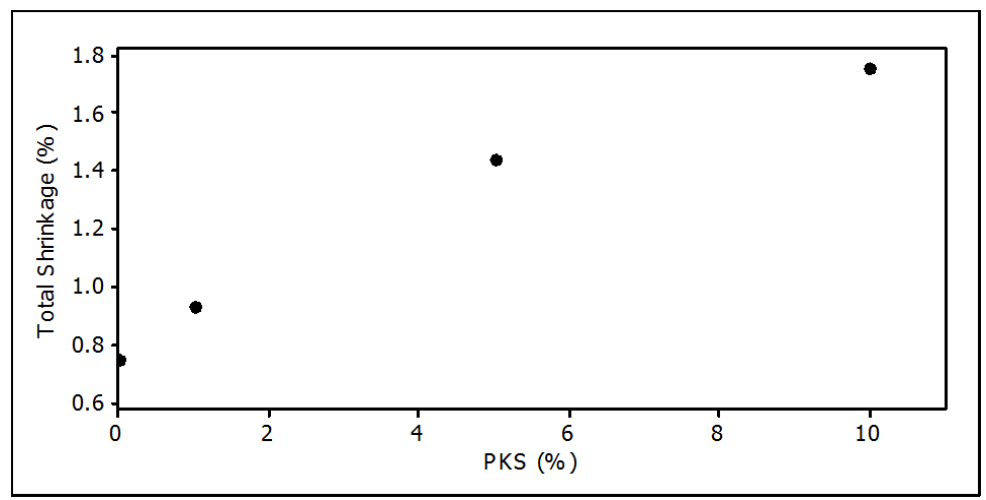

Fig. 2. Total shrinkage of brick.

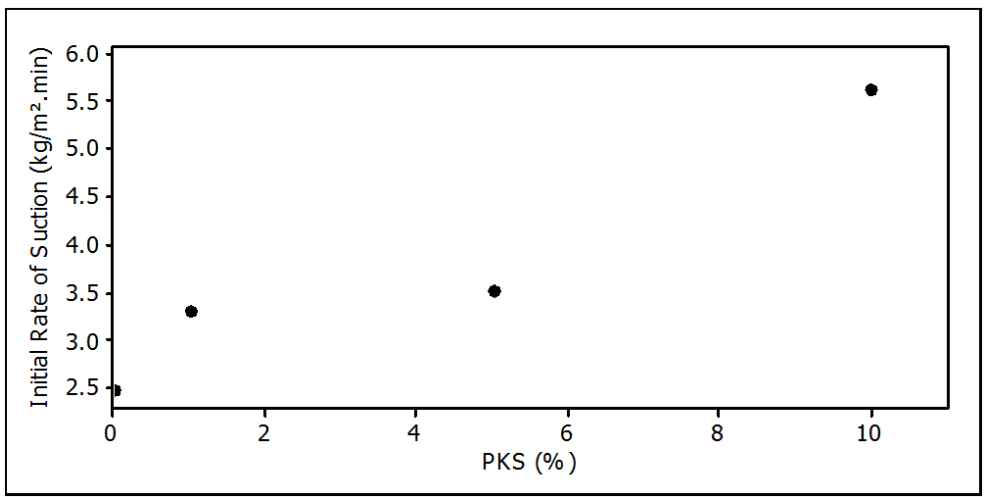

Fig. 3. Initial rate of suction of brick.

\subsubsection{Water absorption}

Water absorption of the manufactured brick is presented in Fig. 4 where water absorption values of the samples were varied within $12.84 \%$ to $17.75 \%$ depending on the percentage of waste content. As the PKS content increased, the value of water absorption also increased. Based on the result, $\mathrm{CB}$ tends to absorb lowest water absorption with $12.84 \%$ compared to others PKSBs. The results also found that increasing $1 \%$ to $10 \%$ of PKS had increased water absorption of brick with $14.62 \%, 17.09 \%$ and $17.75 \%$ respectively. The justification of this behaviour could be related to the organic matter in PKS which eliminate during sintering process thus created numerous pores. According to [4], water absorption of manufactured brick can be classified as Engineering Brick B and brick for Damp Proof Course 2 which only applicable for non-loading application. 


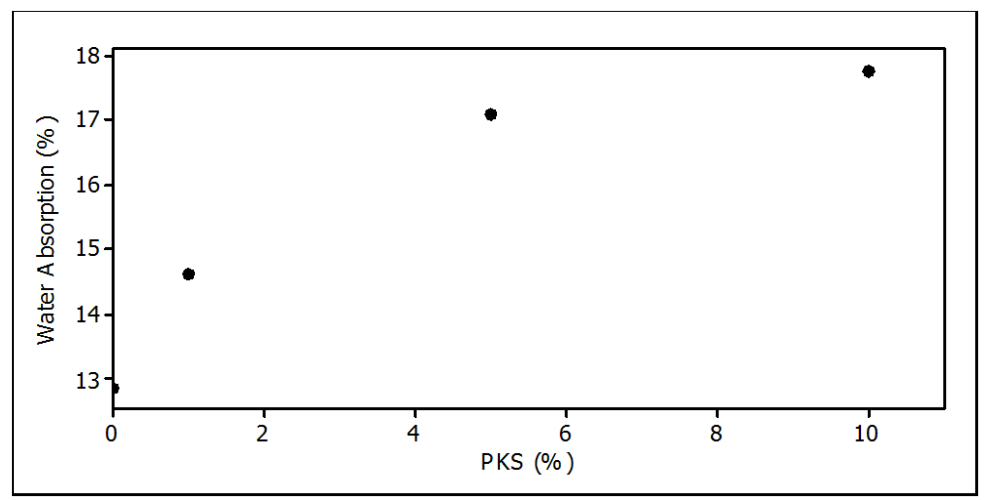

Fig. 4. Water absorption of brick.

\subsubsection{Porosity}

Porosity of the manufactured bricks is presented in Fig. 5 where porosity values of the samples were varied between $14.65 \%$ to $21.35 \%$, depending on the percentage of waste content. Based on the figure, PKSB10\% gives the highest porosity $(21.34 \%)$ followed by PKSB5\% and PKSB1\% with $17.72 \%$ and $16.32 \%$ respectively. Meanwhile, CB was obtained lowest porosity with $14.65 \%$. It was acclaimed that high porosity could reduce thermal conductivity of brick as well as beneficial for higher energy saving in building application [10-11].

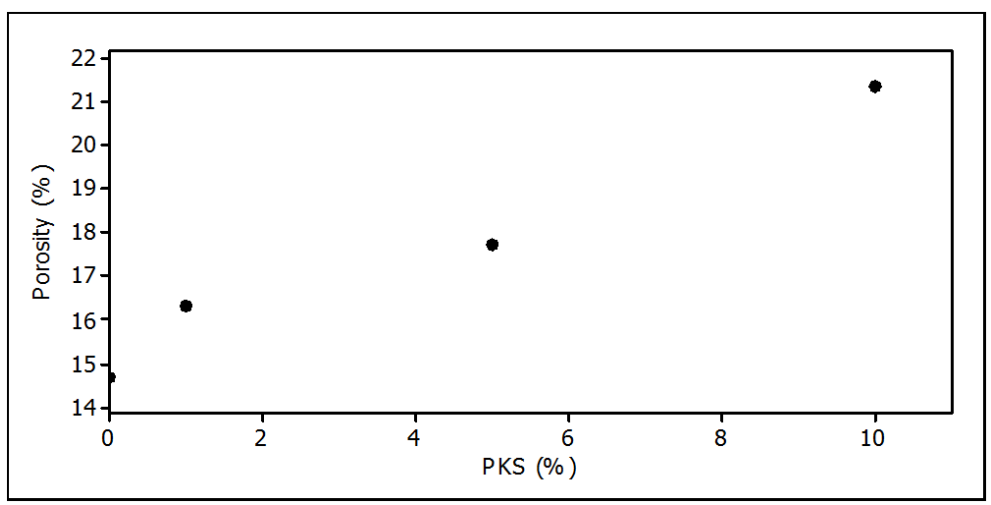

Fig. 5. Porosity of brick.

\subsubsection{Compressive strength}

Compressive strength of the manufactured bricks is presented in Fig. 6 where compressive strength values of the samples were varied between $6.75 \mathrm{MPa}$ to $19.52 \mathrm{MPa}$ depending on the percentage of waste content. As the PKS content increased, the value of compressive strength is decreased. From the figure, PKSB1\% obtained the highest compressive strength with $24.61 \%$ followed by others PKSB with $12.50 \mathrm{MPa}$ (PKSB5\%) and $6.75 \mathrm{MPa}$ (PKSB10\%). Meanwhile, compressive strength for $\mathrm{CB}$ was recorded as $19.52 \mathrm{MPa}$. It is expected that PKSB10\% contained high organic matter thus leaves numerous pores during sintering process which is lead to reduce the strength of brick. According to [4], all the 
brick were above the minimum requirement and be applied for non loading construction application.

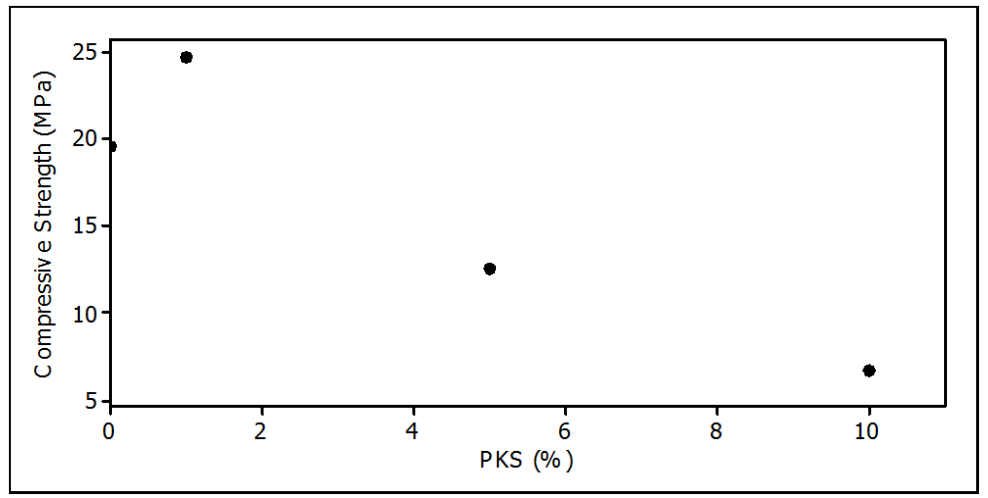

Fig. 6. Compressive strength of brick.

\section{Conclusions}

PKS can be regarded as a potential addition to raw materials used in the manufacturing of fired clay brick. Incorporation of clayey soil and PKS can be used as building material with acceptable physical and mechanical properties match with the requirement of non-loading application. It was suggested that incorporation of $1 \%$ of PKS into fired clay brick could be an alternative method to reduce abundant PKS waste in landfill. Mixing 1\% of PKS is recommended as it produced highest compressive strength and lower in density, which are desirable in producing green building product.

The results presented in this paper are part of an ongoing postgraduate research. The authors would like to thank the Faculty of Civil Engineering, UTHM for this study.

\section{References}

[1] S.M.S. Kazmi, S. Abbas, M.J. Munir, and A. Khitab, Exploratory study on the effect of waste rice husk and sugarcane bagasse ashes in burnt clay bricks, J. of Building Engineering, 7, 372-378, (2016)

[2] A.A. Kadir and A. Mohajerani, Effect of heating rate on gas emissions and properties of fired clay bricks and fired clay bricks incorporated with cigarette butts, Applied Clay Science, 104, 269-276, (2015)

[3] A.A. Kadir, N.A. Sarani, and A.M. Leman, Testing on building material using waste material in fired clay brick, Materials Science Forum, 803, 330-336, (2014)

[4] BS 3921, Specification for clay bricks, British Standard (BS), London, United Kingdom, (1985)

[5] The Brick Industry Association BIA, Technical Notes $3 A$ - Brick Masonry Material Properties, Technical Notes on Brick Construction, The Brick Industry Association, Reston, Virginia, USA, (1992)

[6] A.G. Celik, T. Depci, and A.M. Kılıc, New lightweight colemanite-added perlite brick and comparison of its physicomechanical properties with other commercial lightweight materials, Construction and Building Material, 62, 59-66, (2014)

[7] P. Panedpojaman and V. Sae-Long, Use of palm oil fuel ash in lightweight brick industry, Academic J. of Science, 2(2), 163-170, (2013) 
[8] A.A. Kadir, A. Mohajerani, F. Roddick and J. Buckeridge, Density, strength, thermal conductivity and leachate characteristics of light-weight fired clay bricks incorporating cigarette butts, Proc. of the World Academy of Science, Engineering and Technology, 53, 1035-1040, (2009)

[9] BS EN 771-1, Specification for masonry units part 1: Clay Masonry units, British Standard, BSI Standards Publication, London, United Kingdom, (2011)

[10]M. Sutcu, Influence of expanded vermiculite on physical properties and thermal conductivity of clay bricks, Ceramics Int., 41(2), 2819-2827, (2015)

[11]D. Eliche-Quesada, S. Martínez-Martínez, L. Pérez-Villarejo, F.J. Iglesias-Godino, C. Martínez-García, and F.A. Corpas-Iglesias, Valorization of biodiesel production residues in making porous clay brick, Fuel Processing Technology, 103, 166-173, (2012) 